Volume: 11 Issue: 1 Year: 2014

\title{
Adaptive learning systems: Supporting navigation with customized suggestions
}

\author{
Sibel Somyürek ${ }^{1}$ \\ Halil İbrahim Yalın ${ }^{2}$
}

\begin{abstract}
The aim of this study was to share the results from an experimental research which investigate the effects of link annotations in an educational hypermedia on students' navigation. This study was conducted through a post-test only control group design with 67 undergraduate students. The voluntary research participants were randomly assigned into the experimental and control group. The required data were collected through an academic achievement test, the Motivated Strategies for Learning Questionnaire, the Non-Linear Media Disorientation Assessment Tool, a questionnaire about users' opinions and user logs. The findings showed that the perceived disorientation scores and revisitation rates were significantly lower for the learners who studied in the adaptive environment than those in the non-adaptive environment. It was observed that students' non-sequential navigation in experimental group increased significantly and they followed the system's advices.
\end{abstract}

Keywords: Adaptive Educational Hypermedia; Navigation; Disorientation

\section{Introduction}

E-learning platforms are being widely used by numerous educational institutions and commercial companies to train students and employees. However, due to the overabundance of information and possible navigational paths that a user can follow, users face a number of common difficulties associated with these environments (Brusilovsky, 1998; Conklin, 1987; Hammond, 1989). Adaptive web-based learning systems, which have focused on providing personalized educational content and learning paths, are drawing increased attention among researchers and system designers' since their potential to solve navigation problems. Although there is a general agreement on the power of these systems to reduce disorientation problems, there is a lack of experimental research findings. This study aimed to share the results from an experimental

\footnotetext{
1 Instructor. Dr., Gazi University, Faculty of Education, Department of Computer Education and Instructional Technologies, ssomyurek@gazi.edu.tr

2 Prof. Dr., Eastern Mediterranean University, Faculty of Education, hiyalin@gazi.edu.tr
} 
Somyürek, S. \& Yalın, H. İ. (2014). Adaptive learning systems: Supporting navigation with customized suggestions. International Journal of Human Sciences, 11(1), 55-77. doi: 10.14687/ijhs.v11i1.2663

research which investigate the effects of link adaptations in an educational hypermedia on students' navigation in terms of perceived disorientation, revisitation rates and non-sequential navigation.

\section{Disorientation}

Web-based systems provide instant access to a wide range of knowledge resources and flexible navigation which provides an opportunity for students to navigate freely by eliminating the requirement to follow a previously created path (Alomyan, 2004). Web-based systems also give the responsibility of making decisions, such as where to go, how to reach current location and what to display next, to the students (Zhu, 1996, p. 26). However, navigation in web-based learning system is a complex task, and most web users experience occasional difficulties when browsing and lose their ability to find their way within large-scale environments (Höök, Sjölinder and Dählback, 1996; Chen and Macredie, 2002; Herder and Juvina, 2004; Kim and Hirtle, 1995; Dillon et al., 1990; Nielsen, 1990). One of the major and common navigation problem faced by students studying in web-based systems is disorientation, defined as "an individual's tendency to lose her/his sense of location and direction in nonlinear documents" (Conklin, 1987; Hammond, 1989; Beasley and Waugh, 1995; Chen, 2002).

Disorientation decreases the usability of multimedia (Demirbilek, 2004) and negatively affects individuals' navigation and knowledge search behaviors in hypermedia (McDonald \& Stevenson, 1998). Due to the students need to orient themselves in the hypermedia, their mental processes divided, and as a result they can pay less attention to their learning task (Tripp and Roby, 1990; Kim and Hirtle, 1995). In addition, missing some of the relevant content may decrease the students' learning performance (Mitchell, Chen, \& Macredie, 2005; Amadieu et al., 2009). Adaptive hypermedia systems are thought to prevent disorientation problems by limiting browsing space, providing annotations for the links, hiding some irrelevant links or suggesting the best link to follow (Koch, 2000, p:3).

\section{Motivations of the Study}

Although many researchers suggested that navigational advice would help to reduce disorientation problem (Ruttun \& Macredie, 2012; Chen, 2002; Brusilovsky, 1998; de La Passardiere \& Dufresne, 1992; Jonassen, 1992; Costa Pereira et al, 1991), there are only a few empirical evidence in the literature (Juvina and Herder, 2005) which focused on the effects of link annotations on users' disorientation. The requirement of more experimental studies about the 
Somyürek, S. \& Yalın, H. İ. (2014). Adaptive learning systems: Supporting navigation with customized suggestions. International Journal of Human Sciences, 11(1), 55-77. doi: 10.14687/ijhs.v11i1.2663

effects of link annotations in adaptive learning systems on students' navigation was the primary motivation for this study.

Prior domain knowledge effects navigation in web based systems and more prior knowledge provides needed cognitive resources for browsing in non-linear platforms (McDonald \& Stevenson 1998; Rouet, 2003; Amadieu et al, 2009). In the Introduction to Computing course, students typically have different levels of prior knowledge and interest which is a substantial problem in traditional classroom settings. In these courses, we generally observe that students having more prior knowledge easily become bored in first lessons or introduction to each topic and don't listen ongoing lessons. As a result, they also cannot learn new concepts/practices for them. At the same time, students having more interest always want to learn extra details and their classmates become angry or bored to their questions. For that reason, developing and using an adaptive learning system is important for Introduction to Computing course. Adaptive system that used in this study was including link annotations in content map to guide students about appropriate nodes according to their prior knowledge, their interests and nodes prerequisite relations. In this context, the second motivation for the present study was to provide experimental research findings about the effects of our educational adaptive system on the navigation of students studying to Introduction to Computing course.

\section{The Aim of the Study}

The purpose of this study was to investigate the effects of link adaptations in an educational hypermedia on students' navigation. With this general aim, our hypotheses were:

1. The experimental group would have lower perceived disorientation scores than the control group,

2. The experimental group would have higher rate of content map use than would the control group,

3. The experimental group would have lower revisitation rates than the control group,

4. The students who use adaptive educational hypermedia follow the system's recommendations.

\section{Methodology}

This study was conducted through a posttest control group quasi-experimental design using 75 undergraduate students in a large public university in Turkey. First, prior to assigning the students 
Somyürek, S. \& Yalın, H. İ. (2014). Adaptive learning systems: Supporting navigation with customized suggestions. International Journal of Human Sciences, 11(1), 55-77. doi: 10.14687/ijhs.v11i1.2663

into the experimental and control group, all participants were administered the Motivated Strategies for Learning Questionnaire (MSLQ) and a pre-test. After collecting data with these instruments, participants were first rank ordered and then randomly assigned to two groups of similar sizes (experimental $n=37$, control group $n=38$ ) based on their perception of selfefficacy measured by MSLQ and pre-existing knowledge measured by pre-test.

The independent variable of the research was the web-based learning environment with two levels, the adaptive web-based learning environment and the non-adaptive web-based learning environment. The dependent variables were perceived disorientation, revisitation rates and the rate of content map use.

First and second year undergraduate students studying the course "Introduction to Computing" at Gazi University selected as research participants because learning environment included topics in computer aligned with the second year curriculum. Another reason was, in the Introduction to Computing course, students typically have different levels of prior knowledge and their interest in computers and preferences about learning content also differ. The adaptive systems may suggest relevant topics based on the students' prior knowledge, offer additional detailed information to those with more prior knowledge/interest or include alternative media types and identify the most relevant one based on the students' preferences. Therefore, the adaptations may be useful in this course.

Students were domain novices and they had never used before systematically web-based instructional environment for any other course. A total of 67 out of 75 students were used for the data analysis with eight cases deleted because of missing values, as they did not complete the applications or the questionnaires. There were 32 research participants in the experimental group and 35 research participants in the control group. Of the participants working in the adaptive environment, $78.12 \%$ were female (25 students), and the remaining $21.88 \%$ were male (7 students). Of the participants working in the non-adaptive environment, 51.43\% were female (18 students) and the remaining $48.57 \%$ were male (17 students).

\subsection{Learning material}

\subsubsection{General properties}

A web-based learning environment in domain of Information and Communication Technologies in Education was developed for the experiment. The content of learning environment was focused on 
Somyürek, S. \& Yalın, H. İ. (2014). Adaptive learning systems: Supporting navigation with customized suggestions. International Journal of Human Sciences, 11(1), 55-77. doi: 10.14687/ijhs.v11i1.2663

to teach the students about basic skills needed to use the document and word processing software

"Microsoft Office Word." The web-based learning environment was developed using PHP (a server-side scripting language), MySQL database, and in order to increase user-software interaction, Ajax technology. The content of the learning environment included 7 main sections, with 94 topics and 22 additional explanations. Two versions of the instructional materials for each topic were created, either by videos in which the content was captured audio-visually using screenshot programs or in textual documents supported with visuals. These general properties were the same for either adaptive or non-adaptive learning environment.

\subsubsection{Adaptive web-based learning environment}

In designing the adaptive web-based learning environment, we used ideas from the literature about the four components of an adaptive learning system (De Bra, 1999; Brusilovsky, 1998; Butz, Hua, and Maquire, 2006; Zhang and Ghorbani, 2007; Weber, 1999). In doing so, we have carefully considered the existing technologies and approaches about developing the components; domain model, student model, inference mechanism and adaptations. The functionality of each component within our adaptive system is detailed below.

\subsubsection{Domain model}

The domain model of the current system formed as a data repository that consisted of sections, sub-sections, topics and contents depending on the learning objectives for the Microsoft Office Word software. To construct domain model as a semantic network, prerequisite relations between the topics which means a topic or some topics has to be learned before a subject, were defined. In addition to prerequisite relations, additional explanations which consisted of more detailed information about some subjects were considered in the domain model. Then expert opinions were gathered about the domain model. Taking into consideration feedback and corrections from the experts, the domain model was reorganized.

Due to the literature emphasis on students lacking prerequisite knowledge do not significantly profit from instruction at all (Tobias, 1981; cited by Jonassen \& Grabowski, 1993 pp. 420), we considered prerequisite relations in the domain model. In the domain model of the system, some topics did not have any prerequisites, some of them had only one prerequisite and the others had multiple prerequisites. Furthermore, for some topics, completing one of the multiple prerequisites was sufficient; however, for other topics, the completion of all of the prerequisite topics was required. If learning a topic depends on any of the multiple prerequisites, "or" condition was 
Somyürek, S. \& Yalın, H. İ. (2014). Adaptive learning systems: Supporting navigation with customized suggestions. International Journal of Human Sciences, 11(1), 55-77. doi: 10.14687/ijhs.v11i1.2663

defined among the prerequisites. If several prerequisites has to be completed to learn a topic, a relation based on "and" condition was defined. If both conditions were exist, a relation based on both "and" and "or" conditions was defined. For example, to learn the Paste subject, the students were required to have knowledge about Selecting The Text Topic and either the Cut or Copy topics as shown in figure 1.

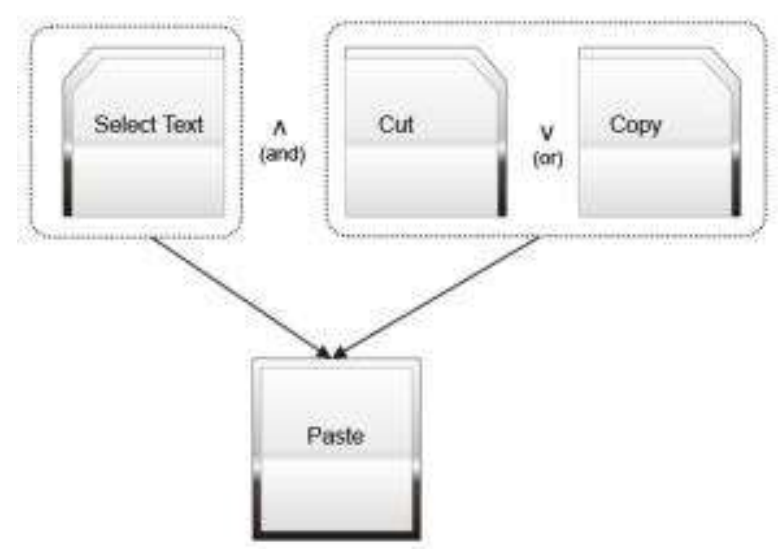

Figure 1: An Example of a Prerequisite Relation that Involves both the "and" and "or" Conditions among the Subjects

Additional explanations were created for 22 of the 94 subject topics. For example, for the Format Toolbar topic, in which format toolbar components were explained, the Customization of Format Toolbar topic was stated as the additional explanation. As in other subject contents, additional explanations were prepared in two different ways: as textual documents supported with visuals and videos. All of the information including the prerequisite relations among the subjects and additional explanations in the domain model was recorded in the database.

\subsubsection{Student model}

The student model of the current system focused on the following three student characteristics:
a. The student's knowledge about the subjects,
b. The student's media preference during the learning process,
c. The student's additional explanation display preference related with the subject s/he studied.

The structure of the first information in this system was domain-specific which describes the students' knowledge level related to the course content. The other two information were domainindependent that based on students' behaviors. 
Somyürek, S. \& Yalın, H. İ. (2014). Adaptive learning systems: Supporting navigation with customized suggestions. International Journal of Human Sciences, 11(1), 55-77. doi: 10.14687/ijhs.v11i1.2663

To gather data related to the three student characteristics listed above, the following methods were used:

- When a student logged on to the system for the first time, he/she was presented a pre-test. Using the answers given in the pre-test, the student's pre-existing knowledge about any subject topic in the learning environment was assessed.

- The usage information obtained throughout the interaction of the user with the system provided to gather domain-independent information and to update domaindependent and independent information. When the user opened or closed any additional explanation, the information about the student's additional explanation display preference was updated. Similarly, when the user changed the presentation type of a content interacting with the system, the information about the student's media preference was updated. When the user visited a page and displayed any content, information about students' knowledge was updated.

In the student model of our learning system, the information was stored using continuous variables. To reach and update the variable values used for student modeling, the necessary information was recorded in the database. In our system we used the overlay model and a Bayesian network. The detailed information about the structure of the Bayesian network used in this software is provided in the inference mechanism section.

\subsubsection{The inference mechanism}

The inference mechanism of this system was formed using a Bayesian network to compute the posterior probabilistic prediction. This probabilistic inference in the current adaptive system computed the posterior probabilities for the following three situations:

1. Is topic appropriate for student?

2. Is additional information shown or hidden?

3. Which type of content presentation is used?

To determine the first situation, suitability of any subject topic for a student, the Bayesian network structure shown in Figure 2 is used. Each of the nodes in Figure 2 represents a variable that affects the suitability state of the subject. The directed edges show casual links between variables. For example "suitability of any subject topic" depends on two factors (variables); "state of knowing the prerequisite" and "state of knowing the subject." There is a set of values that 
Somyürek, S. \& Yalın, H. İ. (2014). Adaptive learning systems: Supporting navigation with customized suggestions. International Journal of Human Sciences, 11(1), 55-77. doi: 10.14687/ijhs.v11i1.2663

defines the alternative values that each variable can take in the Bayesian network. For example, the "Prior knowledge about the prerequisite subject" variable has two states, "the student has prior knowledge" or "the student does not have prior knowledge." The probability values given at the beginning for these cases are labeled as prior probabilities. For example, the probability that "the student has prior knowledge" about any subject is 0.5 , as is the probability that "the student does not have prior knowledge". Conditional probabilities among the nodes that include causeeffect relations in Bayesian networks are determined. Finally, in the Bayesian network, for a given variable, the posterior probability is computed belong to prior probabilities, casual relations and observations. This posterior probability value is considered to be the prior probability value in the next calculation process.

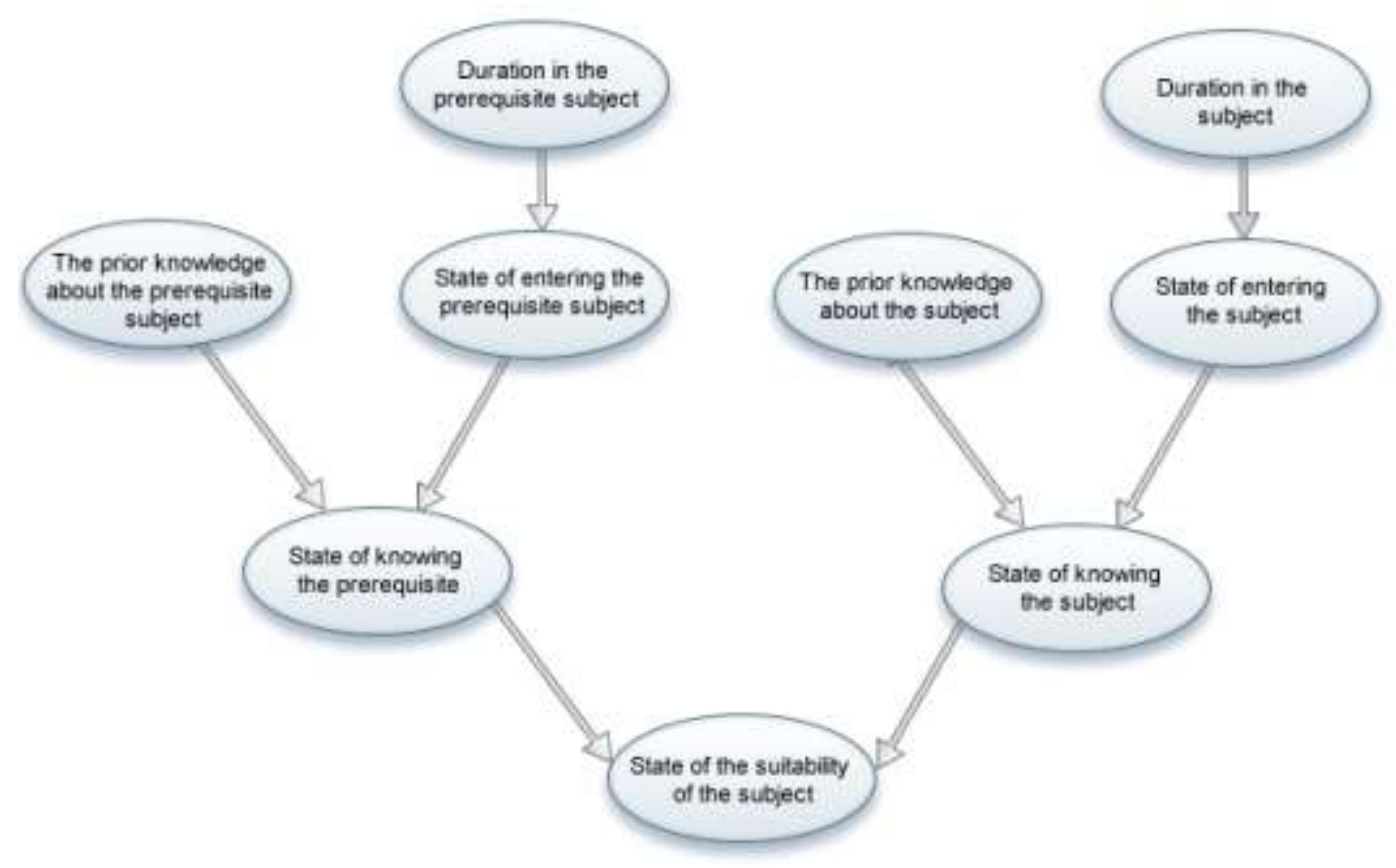

Figure 2: Bayesian Network Structure for Determining the Suitability of a Subject

The aforementioned variables, the set of values of these variables, the prior probability values of these variables, the evidences regarding the variables at a given moment and the relations among the variables are used for the probabilistic inference about the suitability of a subject. From the values obtained at the end of this probabilistic inference, one of three results, "appropriate", "already known" and "not appropriate", is identified for the suitability of a subject. A topic is defined as "appropriate" if student has enough knowledge about the prerequisite subjects and does not have sufficient knowledge about the subject. A topic is defined as "already known" if 
Somyürek, S. \& Yalın, H. İ. (2014). Adaptive learning systems: Supporting navigation with customized suggestions. International Journal of Human Sciences, 11(1), 55-77. doi: 10.14687/ijhs.v11i1.2663

student has enough knowledge about the subject. A topic is defined as "not appropriate" if student has not enough knowledge about prerequisite subjects.

\subsubsection{Adaptations}

In the developed system, one navigation adaptation and two content adaptations were realized belong to the inferences.

\section{Navigation adaptation}

The Link annotation method was used to show the appropriateness of topics as an adaptive navigation support in the software. This adaptation modified links with visual cues to guide users if they were ready to learn the topic. The nodes to each topic were annotated with different icons and colors displayed on the content map on the left side of the software, which is visible and usable at any time. The icon/font combination displayed on the content map categorized topics into the following three groups based on the results obtained probabilistic inference:

1. appropriate -

2. not appropriate-

3. already known

The content map including link annotations in adaptive web-based learning environment is displayed in figure 3 . 
Somyürek, S. \& Yalın, H. İ. (2014). Adaptive learning systems: Supporting navigation with customized suggestions. International Journal of Human Sciences, 11(1), 55-77. doi: 10.14687/ijhs.v11i1.2663

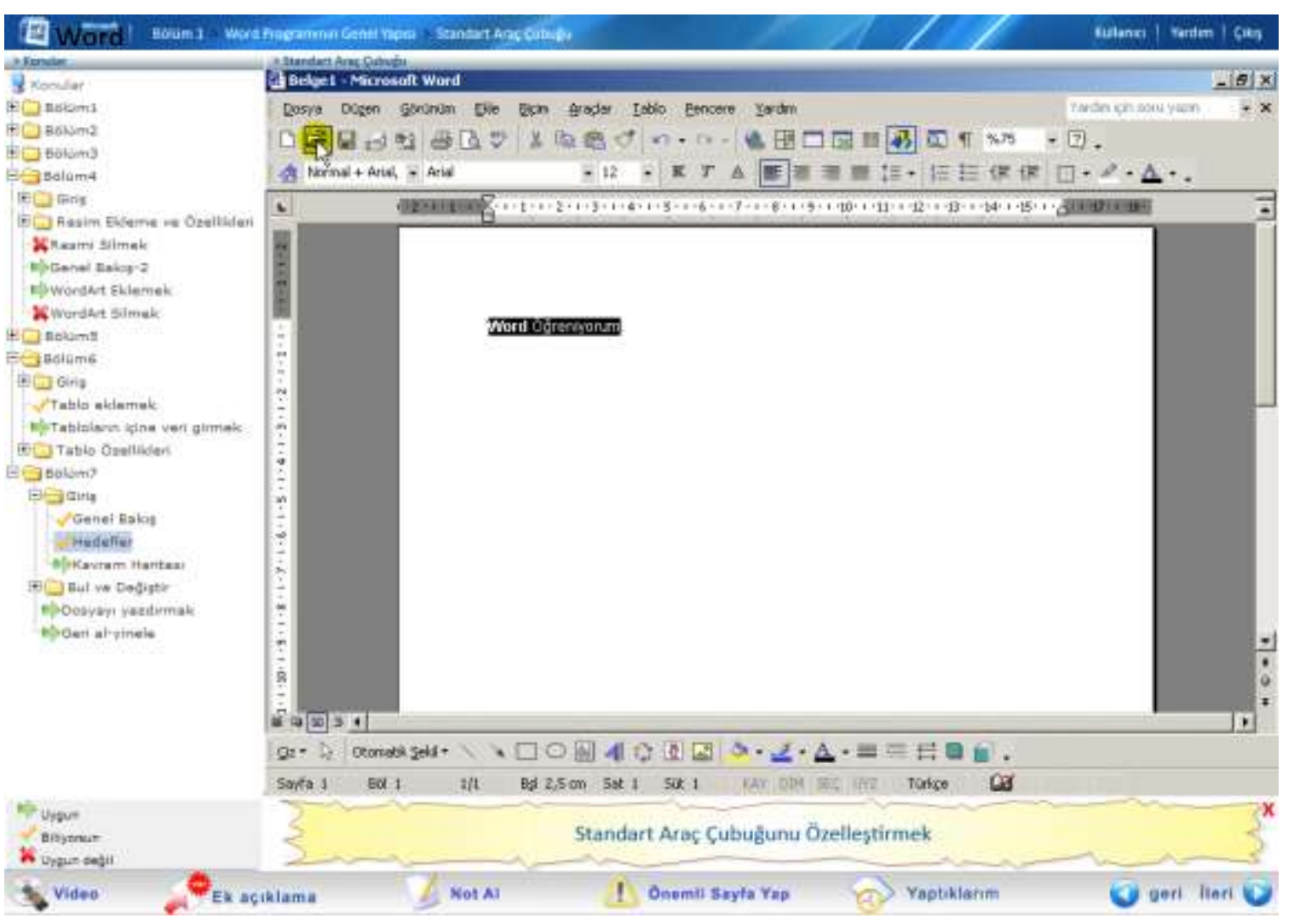

Figure 3: Interface of the Adaptive Web-based Learning Environment

Students were not required to follow the directions of the topics provided to them in the content map. If the students clicked on a topic that was annotated as "not appropriate- $\boldsymbol{*}$ " in the content map, a warning screen appeared. On this warning screen, prerequisite subjects to learn the topic were listed. The student could study any of the listed subject s/he desired by clicking on them. If the student did not want to study the prerequisite subjects, then s/he could study the topic s/he selected in the content map, even if it was not suitable. On the warning screen, prerequisite subjects were displayed on a green background, similar to the suitable subjects displayed in the content map, and the subjects that were not suitable to study were displayed on a red background. In Figure 4, the warning screen display is shown. When the student studied by clicking on one of the subjects that exist among prerequisite subjects given in the warning screen or in the content map, the suitability of the subjects related to that subject was reevaluated, and the icons $(\boldsymbol{\sim}, \boldsymbol{\sim})$ were updated based on the obtained values. 
Somyürek, S. \& Yalın, H. İ. (2014). Adaptive learning systems: Supporting navigation with customized suggestions. International Journal of Human Sciences, 11(1), 55-77. doi: 10.14687/ijhs.v11i1.2663

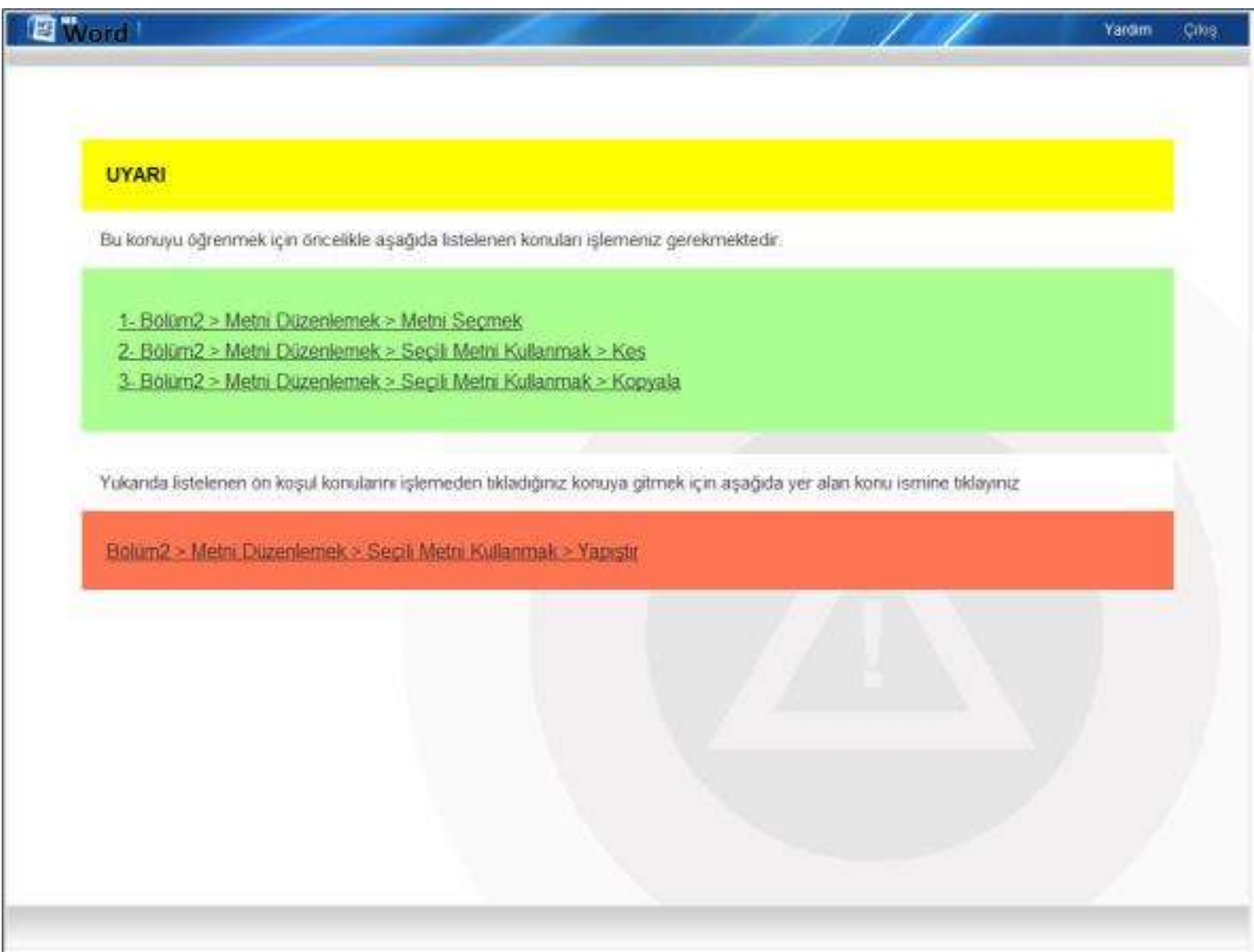

Figure 4: Warning Screen That Appeared When a Student Clicked on an Inappropriate Subject

\section{Content adaptation}

Additional explanation and explanation variants methods were used to adapt the content of learning system. When the user clicked on a node, if there was an additional information section containing extra knowledge about the subject, the software showed/hide the additional explanations. Additional information was either displayed or not depending on the value obtained by the inference mechanism on the additional information state. Figure 3 depicts a screen shot in which additional information was clearly displayed at the bottom while the student studied the subject. When the student studied additional information by clicking on it or closed it by clicking the "turn the information off" button, the additional information preference was updated.

The explanation variants method was used to show students the appropriate content presentation type (video or textual documents supported with visuals) when they clicked on each node. The content determination presentation type is determined according to the student's previous preferences. Each time the user changed the presentation type, the presentation preference was updated, and a new value was calculated for the presentation type. 
Somyürek, S. \& Yalın, H. İ. (2014). Adaptive learning systems: Supporting navigation with customized suggestions. International Journal of Human Sciences, 11(1), 55-77. doi: 10.14687/ijhs.v11i1.2663

\subsection{Data Collection Tools and Procedure}

At the beginning of the treatment, two academic achievement tests were administered to measure students' pre-existing knowledge on the domain. One of the academic achievement tests was in a multiple-choice format and one in a practical test format. According to the pre-application of the multiple-choice achievement test, KR-20 Reliability Coefficient was calculated to be 0.72 . After computing discriminating power of each item, 15 items with discrimination coefficients of less than 0.20 were removed from the test, and a multiple-choice achievement test with 40 questions was created. The average difficulty level of the items in the test was 0.53 .

Then to collect data about the students' perception of self-efficacy with regard to the course, the MSLQ was administered. The MSLQ was originally developed by Pintrich, Smith, Garcia and McKeachie (1991) and translated into Turkish by Büyüköztürk et al. (2004). This likert-type questionnaire includes two-part. First part assesses college students' motivational orientations and second part assesses their learning strategies (Pintrich, et al., 1991). Participants rated each statement for a particular college course on a continuum from very true of me (7) to not at all true of me (1). For the purposes of this study, 8-item section of the MSLQ that assessed selfefficacy sub factor was used.

After collecting data about students' pre-existing knowledge and perception of self-efficacy, research participants were randomly assigned into the experimental and control group, matching through these personal characteristics. Experimental group assigned to the adaptive learning system and control group assigned the non-adaptive one. In the second week the participants were introduced to system through a step-by-step demonstration of all features available within system. In this familiarization session system had a different content "Research Techniques". After introduction part, both students in experimental and control group studied this content in the web learning system.

In the third, fourth and fifth weeks, during two-hour sessions the experimental group worked at the adaptive web-based learning system and experimental group worked at the non-adaptive system including the content about basic skills needed to use the document and word processing software "Microsoft Office Word." At the end of the three-week course, the students were asked to complete a non-linear media disorientation assessment tool and an on-line questionnaire. In addition, data were collected through user logs to compute revisitation rates and content map using rate. 
Somyürek, S. \& Yalın, H. İ. (2014). Adaptive learning systems: Supporting navigation with customized suggestions. International Journal of Human Sciences, 11(1), 55-77. doi: 10.14687/ijhs.v11i1.2663

To assess the students' perceived disorientation, the Non-Linear Media Disorientation Assessment Tool, which was originally developed by Beasley and Waugh (1995) and translated into Turkish by Karadeniz and Kllıç (2004), was used. This tool is a 5-point Likert-type selfreport scale with seven questions. The lowest score that can be obtained from the scale is 7 , whereas the maximum score is 35 . Lower scores on this scale indicate lower perceived levels of disorientation and higher scores indicate higher disorientation levels.

A questionnaire with 3 parts including open-ended questions was conducted at the end of the course. The first part focused on the participants' demographic information, the second part was related to the participants' satisfaction about the system, and the third part was designed to assess students' opinions regarding the components of the environment and learning experiences.

In the literature, it has been observed that some measurements can be calculated by analyzing navigation data to predict users' disorientation. In the current study, each of the students' navigation trails during the application was recorded in the MySQL database. Using these recorded data, the revisitation rate, which is an objective measurement, was calculated. Revisitation rate is average rate of revisits to pages which were visited at least twice (Herder, 2003). The revisitation rate is calculated with the mean number of returns per node. For example, in a navigation that included the pages visited and number of visits shown in Table 1, the revisitation rate is calculated with the formula below and the revisitation rate of a student who followed that navigation structure is computed as 3 .

Table 1: A Sample of Navigation Structure

\begin{tabular}{ll}
\hline Pages & Number of Visits \\
\hline What is Word? & 1 \\
\hline Running the Word Program & 2 \\
\hline $\begin{array}{l}\text { General Structure of the Word } \\
\text { Program }\end{array}$ & 1 \\
\hline Create a New File & 4 \\
\hline Save a File for the First Time & 5 \\
\hline Save Changes to the File & 3 \\
\hline Open a File & 2 \\
\hline Save the File As & 1 \\
\hline Close the File & 2 \\
\hline Close Word & 1 \\
\hline
\end{tabular}

Return rate $=\frac{(2+4+5+3+2+2)}{6}=3$ 
Somyürek, S. \& Yalın, H. İ. (2014). Adaptive learning systems: Supporting navigation with customized suggestions. International Journal of Human Sciences, 11(1), 55-77. doi: 10.14687/ijhs.v11i1.2663

The rate of students' use of the content map as a navigation tool was calculated according to looking at their overall use of navigation tools on both days. The percentage of content map use was calculated by taking into account the number of times students used the content map and the total number of hits on any of the navigation tools. For example, if visited pages and used navigation tools to navigate among these pages is as shown in Table 2, the rate of using of the content map as a navigation tool is calculated with the below formula and computed as $33.33 \%$.

Table 2: An Example of Navigation Tool Use

\begin{tabular}{ll}
\hline Pages & Navigation Tool Used \\
\hline What is Word? & Button for System Login \\
\hline Running the Word Program & Forward \\
\hline $\begin{array}{l}\text { General Structure of the Word } \\
\text { Program }\end{array}$ & Forward \\
\hline Running Word & Back \\
\hline Save File for the First Time & Content map \\
\hline Save Changes to the File & Forward \\
\hline Save File As & Forward \\
\hline Boldface the Text & Content map \\
\hline Adding Bullets & Content map \\
\hline
\end{tabular}

The Rate of Using Content Map as a Navigation Tool $=\frac{3}{9} \times 100=33,33$

\section{Findings}

In this section, the navigations of students studying with adaptive and non-adaptive web-based learning environment are discussed in terms of three factors: perceived disorientation, rate of content map use as a navigation tool and revisitation rate. The findings on these factors are presented below.

\subsection{Perceived Disorientation}

Our first hypothesis was that the experimental group would have lower perceived disorientation scores than the control group. To explore this hypothesis, we computed students' perceived disorientation scores. Then an independent-samples t-test was conducted to compare perceived disorientation scores of control group and experimental group. According to the results in Table 3 , the perceived disorientation scores $(M=13.28, S D=3.35)$ of students studied to the adaptive 
Somyürek, S. \& Yalın, H. İ. (2014). Adaptive learning systems: Supporting navigation with customized suggestions. International Journal of Human Sciences, 11(1), 55-77. doi: 10.14687/ijhs.v11i1.2663

environment were lower than the scores $(M=15.17, S D=3.99)$ of students studied to the nonadaptive environment, $\mathrm{t}(65)=2.08, \mathrm{p}<.05$.

Table 3: Independent t-test Results for Perceived Disorientation Scores

\begin{tabular}{lllll}
\hline Group & Mean & SD & $t$ & p-value \\
\hline Experiment & 13.28 & 3.35 & 2.08 & 0.041 \\
Control & 15.17 & 3.99 & & \\
\hline
\end{tabular}

\subsection{Revisitation Rates}

Revisitation rate is one of the proposed objective measures of disorientation which is computed from log records. Herder (2003) showed that revisitation rate is a good indicator of disorientation in his experimental study $(\mathrm{r}=-0.417 ; \mathrm{p}<0.022)$. To analyze whether there is a significant difference between the revisitation rates of the students studied in adaptive and nonadaptive web-based learning environments, a t-test was performed. The findings from the independent samples t-test are shown in Table 4.

Table 4: Independent t-test Results for Revisitation Rates

\begin{tabular}{lllll}
\hline Group & Mean & SD & $t$ & p-value \\
\hline Experiment & 5.28 & 1.26 & 3.18 & 0.002 \\
Control & 6.34 & 1.43 & & \\
\hline
\end{tabular}

Due to the independent samples t-test analysis, there is a significant difference between the revisitation rates of the students in control and experimental groups, $\mathrm{t}(65)=3.18, \mathrm{p}<.05$. In other words, the revisitation rates $(M=5.28, S D=1.26)$ of students in the adaptive environment are lower than the revisitation rates $(M=6.34, S D=1.43)$ of students in the non-adaptive environment.

\subsection{Preferences in Using Navigation Tool}

To explore whether the adaptations in learning environment effects on the students' navigation tool using preferences, firstly we computed the percentage of content map use. Then, we used independent samples t-test to compare content map use scores of students in experimental and control groups. The summary results of the t-test are presented in Table 4. 
Somyürek, S. \& Yalın, H. İ. (2014). Adaptive learning systems: Supporting navigation with customized suggestions. International Journal of Human Sciences, 11(1), 55-77. doi: 10.14687/ijhs.v11i1.2663

Table 5: Independent t-test Results for Students' Rate of Content Map Use

\begin{tabular}{lllll}
\hline Group & Mean & $S D$ & $t$ & p-value \\
\hline Experiment & .75 & .18 & 3.18 & 0.0006 \\
Control & .44 & .36 & & \\
\hline
\end{tabular}

As it can be seen in Table 4, for the students' rates of content map use as a navigation tool, there was a significant difference between control and experimental group, $t(65)=3.18, p<.001$. The rate of content map use as navigation tool is significantly higher in the adaptive web-based learning environment group $(M=.75, S D=.18)$ than that for the students who studied in the non- adaptive web-based learning environment $(M=.44, S D=.36)$. In other words, when the link annotation method was used in the content map, the students' preference of using content map as a navigation tool increased significantly.

The qualitative data, which were collected through online student questionnaires, also supported this finding. Students stated that "Visual hints in the content map" were one of the most liked features in the adaptive learning environment. Students' responses about the most liked features in the adaptive learning environment were themed into the four major themes; content presentation through video-audio (56.25\%), clear delivery (21.88\%), availability of visual hints in the content map (15.63\%) and opportunity for repetition (15.63\%). This finding becomes more important because it was obtained from an open-ended question, without any prompting from the researcher and the learners were inexperienced web-based system users and had never used a similar system before. Moreover, twenty-six of the students $(81.25 \%)$ thought that the icons in the content map correctly guided them with regard to the relevance of topics and stated the benefits of visual hints on the content map. One student stated: "The content map helped me to a great extent. It allowed moving without having to visit the page I was working on and I could see where I was." Another student stated: "It was helpful for me. I have realized what I was doing and what I needed to do." Considering qualitative results, the reasons for the increased content map use can be explained as following. The opportunity to see non-appropriate subjects in the content map and to navigate to the prerequisite subjects via a warning screen led the user to see the relations between topics and this guidance provided them to feel more comfortable. 
Somyürek, S. \& Yalın, H. İ. (2014). Adaptive learning systems: Supporting navigation with customized suggestions. International Journal of Human Sciences, 11(1), 55-77. doi: 10.14687/ijhs.v11i1.2663

\subsection{Following the Adaptive System's Recommendations}

To determine whether students who studied adaptive learning system follow the system's advices about the suitability of the subjects, the statistics about the number of clicks on the nonappropriate subjects in the content map are given as frequency $(f)$ and percentage $(\%)$ in Table 6.

Table 6: The Number of Students' Clicks on the Inappropriate Topics

\begin{tabular}{lcc}
\hline The Number of Clicks & $\mathrm{f}$ & $\%$ \\
\hline Students who have never clicked & 4 & 12,5 \\
\hline Students who have clicked once & 6 & 18,75 \\
\hline Students who have clicked twice & 9 & 28,125 \\
\hline Students who have clicked three times & 10 & 31,25 \\
\hline Students who have clicked four times & 1 & 3,125 \\
\hline Students who have clicked five times & 2 & 6,25 \\
\hline Total & 32 & 100 \\
\hline
\end{tabular}

As shown in Table 6, the students, clicked on a very small number of inappropriate subjects in the software. It is remarkable that none of the students clicked on inappropriate subject more than five times. Furthermore, four students did not click on any inappropriate subjects. These statistics show that students tend to substantially accept and follow the system's advice about the suitability of subjects.

When a student clicked on inappropriate content ( $\boldsymbol{\otimes})$, a warning screen appeared. On this screen, there was a list of prerequisite subjects that were needed to learn the inappropriate content. The students could then navigate to these prerequisite subjects from this screen or visit the inappropriate content. Twenty-five of the participating students $(78,13 \%)$ reported that to see the list of prerequisite subjects and to access them from the warning screen contributed to their learning. For example a student commented:

"When I attempted to visit a non-appropriate subject, warning screens contributed my learning by showing which subjects to prioritize."

Another student said:

"This way, I cannot start the subject without preparation, and I access information accurately." 
Somyürek, S. \& Yalın, H. İ. (2014). Adaptive learning systems: Supporting navigation with customized suggestions. International Journal of Human Sciences, 11(1), 55-77. doi: 10.14687/ijhs.v11i1.2663

The questionnaires also revealed that link annotations in the content map eased navigation. A response was as following:

"As all details are listed in the content map, navigation was easy."

\section{Discussion}

Adaptive learning systems aim to provide a learning environment that adapts to the each student's personal needs or desires by helping them in finding out the relevant and meaningful information (Brusilovsky, 2003; Chen, 2002; Koch, 2000, p: 3; Güven Smith, 1999, p: 24). One of the two adaptation technologies, navigation adaptation, aims to minimize the problems that an individual may experience during navigation. Link annotation method is based on informing the users about the current state of the nodes (Da Silva et al., 1998; Brusilovsky, 1998; Brusilovsky, Pesin and Zyryanov, 1993). Link annotation technique presents to the user the full hyperspace, but directs the user's attention to the relevant links, with suggesting links to follow (Eklund \& Sinclair, 2000). In this study, the link annotation method was offered to the students in real time through the visualizations associated with the suitability of the subjects (appropriate, already known and not appropriate) in the content map. The inference of whether or not a subject was appropriate was based on the current knowledge of the student and the prerequisite relations among the subjects in the software. Students' current knowledge is important because prior knowledge supplies cognitive resources for navigating the appropriate nodes in a non-linear environment (McDonald \& Stevenson 1998; Rouet, 2003; Amadieu et al, 2009). Prerequisite relations among the subjects are also critical since students lacking prerequisite knowledge which needed to learn the new knowledge do not significantly profit from instruction at all (Tobias, 1981; cited by Jonassen \& Grabowski, 1993 pp. 420). So modeling mechanisms focused on these two concepts.

The findings of the research showed that the visual hints in the content map decreased students perceived disorientation. Disorientation is one of the most cited problems in hypermedia systems (Rivera-Nivar \& Pomales-García, 2010; Amadieu, Tricot \& Mariné, 2010; Oostendrop, Madrid \& Melguizo, 2009; Webster \& Ahuja, 2006; Chen, 2002; McDonald \& Stevenson 1998; Dias \& Sousa, 1997; Ahuja \& Webster, 2001) which results learners can miss at least some of the relevant content in the system and so, may hinder their learning performance (Mitchell, Chen, \& Macredie, 2005). Many researchers suggested that navigational advice would help to reduce this problem (Ruttun \& Macredie, 2012; Chen, 2002; Brusilovsky, 1998; de La Passardiere 
Somyürek, S. \& Yalın, H. İ. (2014). Adaptive learning systems: Supporting navigation with customized suggestions. International Journal of Human Sciences, 11(1), 55-77. doi: 10.14687/ijhs.v11i1.2663

\&Dufresne, 1992; Jonassen, 1992; Costa Pereira et al, 1991), however, there were only a few empirical evidence in the literature which focused on the effects of link annotations on users' disorientation (Juvina and Herder, 2005). Perceived disorientation is a subjective measure of disorientation which is measured by directly asking user to indicate feelings regarding disorientation, using a questionnaire. The empirical results presented in this paper showed that students perceived themselves as less disoriented when they studied through a learning system with link annotations. This result makes an important contribution to the literature while there are limited experimental studies about adaptive annotations effect on disorientation.

Several studies use metrics generated from analyses of user-system interactions data to measure disorientation (Herder and Juvina, 2004; Juvina \& Oostendorp, 2006; Gwidzka and Spense, 2007). For example, Herder (2003) indicated that return rate is strongly associated with disorientation. A significant decrease of the number of repeated visits to the same node for students studied with adaptive navigation technique was reported in some studies (Brusilovsky \& Pesin, 1998). This study also indicated significantly reduced revisitation rate for the students in the experimental group. This result is important as it supports the previous finding that these students who studied in an adaptive environment experienced less perceived disorientation.

To explore the effects of adaptive system on students' navigation, the use of content map among other navigation tools also examined. The results showed that the rate of content map use as navigation tool is significantly higher in the experimental group than control group. The qualitative data, which were collected through online student questionnaires, also supported this finding. Similar results were also obtained in a previous study held by Brusilovsky and Eklund (1998). In their study, which was conducted with 25 undergraduate students using the InterBook system, inexperienced users, who typically preferred to progress sequentially by using "nextprevious" buttons, used the content map with link annotations more often than a "Continue" button that did not include a link annotation. They interpreted this finding as the link annotations encouraged users to navigate non-linearly.

\section{Conclusion}

Adaptive hypermedia, which is a fairly new but quite popular research field, has a great potential for adoption in education, with the capability to present customized pages/links to learners according to their goals, interests or knowledge. The requirement of more empirical studies about the effects of adaptive learning systems on navigation was the primary motivation for this study. 
Somyürek, S. \& Yalın, H. İ. (2014). Adaptive learning systems: Supporting navigation with customized suggestions. International Journal of Human Sciences, 11(1), 55-77. doi: 10.14687/ijhs.v11i1.2663

So, this work examined the effects of an adaptive learning system on students' navigation. The data collected from both the questionnaires and the log-based metrics showed that the adaptations make users' navigation more comfortable by reducing perceived disorientation and revisitation rates. Disorientation is one of the major difficulties associated with the use of hypermedia. Perceived disorientation, a subjective indicator of users' disorientation, and revisitation rates, an objective measure of users' disorientation, were evaluated in this study. The results showed that both measures were significantly lower for experimental group than control group. The presence of link annotations also caused significantly higher content map use as navigation tool. Users enjoyed getting guidance to navigate and they generally follow the system's advices about navigation.

Considering the results of this study, our adaptive web based learning system have proven its successfulness for helping to support students navigation and to reduce their disorientation by providing link annotations according to students prior knowledge and prerequisite relations between the topics. In this context, new web based learning systems and learning-management systems may be developed with adaptations that take account similar user characteristics and domain concept relations. Future studies can also focus limitations and advantages of the adaptive learning environments with larger number of participants who are more experienced studying in web based learning systems. Future investigations may examine different navigation adaptation techniques' effect on students' navigation.

\section{References}

Alomyan, H. (2004). Individual differences: implications for web-based learning design. International Education, 4(4),188-196.

Ahuja, J. S., \& Webster, J. (2001). Perceived disorientation: An examination of a new measure to assess web design effectiveness. Interacting with Computers, 14(1), 15-29.

Amadieu, F., van Gog, T., Paas, F., Tricot, A., \& Mariné, C. (2009). Effects of prior knowledge and concept-map structure on disorientation, cognitive load, and learning. Learning and Instruction, 19(5), 376-386.

Amadieu, F., Tricot, A. \& Mariné, C. (2010), Interaction between prior knowledge and conceptmap structure on hypertext comprehension, coherence of reading orders and disorientation, Interacting with Computers, 22, 88-97.

Beasley, R. \& Waugh, M. (1995). Cognitive mapping architectures and hypermedia disorientation: An empirical study. Journal of Educational Multimedia and Hypermedia, 4(2/3), 239-255.

Brusilovsky, P. (1998). Methods and techniques of adaptive hypermedia. In P. Brusilovsky, A. Kobsa \& J. Vassileva, Adaptive Hypertext and Hypermedia (pp. 1-44). Boston: Kluwer Academic Publishers.

Brusilovsky, P. (2003). Adaptive navigation support in educational hypermedia: The role of student knowledge level and the case for meta-adaptation. British Journal of Educational Technology, 34(4), 487-497. 
Somyürek, S. \& Yalın, H. İ. (2014). Adaptive learning systems: Supporting navigation with customized suggestions. International Journal of Human Sciences, 11(1), 55-77. doi: 10.14687/ijhs.v11i1.2663

Brusilovsky, P. \& Eklund, J. (1998). A study of user model based link annotation in educational hypermedia. Journal of Universal Computer Science,4(4), 429-448.

Brusilovsky, P. and Pesin, L. (1998) Adaptive navigation support in educational hypermedia: An evaluation of the ISIS-Tutor. Journal of Computing and Information Technology 6 (1), 27-38.

Brusilovsky, P., Pesin, L., \& Zyryanov, M. (1993). Towards an adaptive hypermedia component for an intelligent learning environment. In L. J. Bass , J. Gornostaev \& C. Unger, HumanComputer Interaction (Lecture Notes In Computer Science). (pp. 348-358). London: SpringerVerlag.

Butz, C.J., Hua, S. \& Maguire, R.B. (2006). A web-based bayesian intelligent tutoring system for computer programming. Web Intelligence and Agent systems: An International Journal, 4(1), 77 97.

Büyüköztürk, Ş., Akgün, Ö., Kahveci, Ö. \& Demirel, F. (2004). Güdülenme ve öğrenme stratejileri ölçeğinin Türkçe formunun geçerlik ve güvenirlik çalışması. Kuram ve Uygulamada Eğitim Bilimleri, 4 (2), 207-239.

Chen, S. Y. (2002). A cognitive model for non-linear learning in hypermedia programs. British Journal of Educational Technology, 33(4), 449-460.

Chen, S. \& Macredie, R. (2002). Cognitive styles and hypermedia navigation: Development of a learning model. Journal of the American Society for Information Science and Technology. 53(1), 315.

Conklin, J. (1987). Hypertext: an introduction and survey. Computer, 20(9), 17-41.

Costa Pereira, D., Oliveira, A. \& Vaz, J. (1991). Hypermedia and ITS. In A. Oliveira, Hypermedia courseware: Structures of communication and intelligent belp, (pp. 207-212). Amsterdam: SpringerVerlag.

Da Silva, P., Van Durm, R., Duval, H. \& Olivie, H. (1998). Adaptive navigational facilities in educational hypermedia. In Proceedings of the Ninth Association for Computing Machinery Conference on Hypertext and Hypermedia (HT'98). June 20-24, Pennsylvania, United States.

De Bra, P., (1998). Adaptive Hypermedia on the Web: Methods, techniques and applications, Proceeedings of the AACE WebNet'98. 220-225, AACE, Orlando, Fl.

De Bra, P. (1999). Design issues in adaptive web-site development, In Proceedings of the Second Workshop on Adaptive Systems and User Modeling on the WWW. May 11-14, Toronto, Canada.

Demirbilek, M. (2004). Effects of interface windowing modes and individual differences on disorientation and cognitive load in a hypermedia learning environment. Unpublished doctoral dissertation, Florida University.

de La Passardiere, B. \& Dufresne, A. (1992). Adaptive navigational tools for educational hypermedia. In I. Tomek. $4^{\text {th }}$ International Conference on Computers and Learning (ICCAL'92), (pp. 555-567), Berlin: Springer-Verlag.

Dias, P., \& Sousa, A. P. (1997). Understanding navigation and disorientation in hypermedia learning environments. Journal of Educational Multimedia and Hypermedia, 6(2), 173-185.

Dillon, A., McKnight, C., \& Richardson, J. (1990). Navigation in hypertext: A critical review of the concept. In Proceedings of INTERACT: The third IFIP Conference on Human Computer Interaction, (pp. 587-592), UK. London: Springer-Verlag.

Eklund, J. \& Sinclair, K. (2000). An empirical appraisal of the effectiveness of adaptive interfaces for instructional systems. Educational Technology \& Society, 3(4), 165-177.

Eklund, J. \& Zeiliger, R. (1996). Navigating the web : possibilities and practicalities for adaptive navigational support, In Proceedings of The Second Australian WorldWide Web Conference (AUSWEB'96), July 7-9, Gold Coast, Australia.

Güven Smith, A. S. (1999). Application of machine learning algorithms in adaptive web-based information systems. Unpublished doctoral dissertation, Middlesex University.

Gwidzka, J. \& Spense, I. (2007). Implicit measures of lostness and success in web navigation. Interacting with Computers, 19(3), 357-369. 
Somyürek, S. \& Yalın, H. İ. (2014). Adaptive learning systems: Supporting navigation with customized suggestions. International Journal of Human Sciences, 11(1), 55-77. doi: 10.14687/ijhs.v11i1.2663

Hammond, N. (1989). Hypermedia and learning: Who guides whom? In H. Maurer, Computer Assisted Learning. Lecture Notes in Computer Science (pp. 167-181). Berlin: SpringerVerlag.

Herder, E. (2003). Revisitation Patterns and Disorientation. In Proceedings of the German Workshop on Adaptivity and User Modeling in Interactive Systems (ABIS 2003), Karlsruhe, Germany.

Herder, E. \& Juvina, I. (2004). Discovery of individual user navigation styles, In Proceedings of Workshop on Individual Differences in Adaptive Hypermedia ( AH2004'). 40-49, Eindhoven, Netherlands.

Höök, K., Sjölinder, M. \& Dahlbäck, N. (1996). Individual differences and navigation in hypermedia. In Eighth European Conference on Cognitive Ergonomics (ECCE-8) , 10-13 September, Grenada, Spain.

Jonassen, D. (1992). Designing hypertext for learning. In E. Scanlon \& T. O'Shea, New directions in educational technology, (pp.123-130). Berlin: Springer-Verlag.

Jonassen, D. H. \& Grabowski, B. L. (1993). Handbook of individual differences learning an instruction. prior knowledge and achievement. Hillsdale, NJ: Lawrence Erlbaum Associates.

Juvina, I. \& Herder, E. (2005). The impact of link suggestions on user navigation and user perception, In Proceedings of the User Modeling 20025: Tenth International Conference (UM2005), July 24-29, Edinburgh, United Kingdom.

Juvina, I. \& Oostendorp, H. van (2006). Individual differences and behavioral metric involved in modeling web navigation. Universal Access in Information Society, 4(3), 258-269.

Karadeniz, Ş. \& Kilıç E. (2004). Hiper Ortamlarda Kaybolma Ölçeğinin Uyarlama Çalışması. Kuram ve Uygulamada Eğitim Yönetimi Dergisi, 3, 420-429.

Kim, H. \& Hirtle, S. C. (1995). Spatial metaphors and disorientation in hypertext browsing, Behaviour \& Information Technology. 14(4), 239-250.

Koch, N. (2000). Software engineering for adaptive bypermedia systems: Reference model, modeling techniques and development process, Unpublished doctoral dissertation, Ludwig-Maximilians-University of Munich.

Mcdonald, S. \& Stevenson, R. J. (1998). The effects of text structure and prior knowledge on navigation in hypertext. Human Factors, (40)1, 18-27.

Mitchell, T. J. F., Chen, S. Y., \& Macredie, R. D. (2005). Cognitive styles and adaptive web-based learning. Psychology of Education Review, 29(1), 34-42.

Moe, M., \& Blodgett, H. (2000). The Knowledge Web. New York: Merrill Lynch \& Co.

Nielsen, J. (1990). Navigation through hypertext. Communications of the ACM. 33(3), 297-310.

Oostendrop, H. V., Madrid, R. I. \& Melguizo, M. C. P. (2009). The effect of menu type and task complexity on information retrieval performance, The Ergonomics Open Journal, 2, 64-71.

Pintrich, P.R., Smith, D.A.F., Garcia, T. \& McKeachie, W.J. (1991). A Manual for the use of the motivated strategies for learning. Michigan: School of Education Building, The University of Michigan. ERIC database number: ED338122.

Rivera-Nivar, M. \& Pomales-García, C. (2010). E-training: Can young and older users be accommodated with the same interface?, Computers \& Education, 55, 949-960.

Rouet, J. F. (2003). What was I looking for? The influence of task specificity and prior knowledge on students' search strategies in hypertext. Interacting With Computers, 15(3), 409-28.

Ruttun, R. D. \& Macredie, R. D. (2012). The effects of individual differences and visual instructional aids on disorientation, learning performance and attitudes in a Hypermedia Learning System, Computers in Human Behavior, 28, 2182-2198.

Tripp, S.D. \& Robby, W. (1990). Orientation and disorientation in a hypertext lexicon. Journal of Computer-based Instruction, 17(4), 120-124.

Weber, G. (1999). Adaptive learning systems in the world wide web. In Proceedings of the Seventh International Conference on User Modeling (UM '99), June, 20-24, Banff, Alberta, Canada.

Webster, J. \& Ahuja, J. S. (2006). Enhancing the design of web navigation systems: the influence of user disorientation on engagement and performance. MIS Quarterly, 30(3), 661-678. 

International Journal of Human Sciences, 11(1), 55-77. doi: 10.14687/ijhs.v11i1.2663

Zhang, J. \& Ghorbani, A. A. (2007). GUMSAWS: A generic user modeling server for adaptive web systems. In Proceedings of Fifth Annual Conference on Communication Networks and Services Research. (CNSR 2007), (p. 117-124). May 14 - 17, New Brunswick, Canada.

Zhou, Y. \& Evens, M.W. (1999). A practical student model in an intelligent tutoring system. Proceedings 11th IEEE International Conference on Tools with Artificial Intelligence, Evanston, Illinois, 13-18.

Zhu, E. (1996). Hypermedia interface design: the effects of the number of links and the granularity of nodes on students' information searching and learning performance. Unpublished doctoral dissertation, Bloomington University. 